\title{
EFFECTS OF AMPHETAMINE ON INTRACELLULAR RESPONSES OF CAUDATE NEURONS IN THE CAT ${ }^{1}$
}

\author{
J. S. SCHNEIDER, M. S. LEVINE, ${ }^{2}$ C. D. HULL, AND N. A. BUCHWALD \\ Mental Retardation Research Center, Brain Research Institute, University of California, Los Angeles, California 90024
}

Received June 10, 1983; Revised September 21, 1983; Accepted October 19, 1983

\begin{abstract}
The effects of acute administration of amphetamine on membrane potentials and evoked postsynaptic potentials of caudate neurons in cats were assessed using intracellular recording. High doses of amphetamine $(0.5 \mathrm{mg} / \mathrm{kg}$, i.v. $)$ produced a reversible depolarization of the cell membrane in $78 \%$ of cells tested. Low doses $(0.1 \mathrm{mg} / \mathrm{kg})$ had no effect on the resting membrane potential. Long-lasting increases in amplitude of both excitatory and inhibitory components of evoked postsynaptic potential sequences were observed after both high and low doses of amphetamine. These changes were more evident to cortical than to substantia nigra or to intralaminar thalamic stimulation. These results were shown to be independent of the peripheral autonomic actions of amphetamine. These effects appear to be mediated by the ability of amphetamine to alter catecholaminergic mechanisms in the caudate nucleus and suggest that increased dopamine release may have a facilitatory effect on both excitatory and inhibitory synaptic transmission.
\end{abstract}

The present report describes the electrophysiological effects of amphetamine administration on intracellular potentials recorded from caudate neurons. The action of amphetamine on neuronal activity in the central nervous system, and particularly in the basal ganglia, has been the focus of considerable rescarch (Bunney et al., 1973; Rebec and Groves, 1975; Groves and Rebec, 1976; Levine et al., 1980). Amphetamine is believed to exert its neuronal actions by stimulating dopamine (DA) release and blocking its reuptake (Dray, 1980). Particularly in the striatum and substantia nigra, amphetamine has been shown to increase DA turnover and preferentially release newly synthesized DA from nerve terminals (Dray, 1980).

The effects of amphetamine on neuronal activity in the basal ganglia have been studied exclusively with extracellular recording techniques. In rats, intraperitoneal injections produce a dose-dependent biphasic response in caudate neurons consisting of an initial increase followed by prolonged depression of neuronal activity (Groves et al., 1974). Amphetamine also tends to decrease spontaneous firing of dopaminergic substantia nigra neurons (Bunney and Aghajanian, 1973) while it increases spontaneous activity in nondopaminergic substantia nigra neurons (Groves et al., 1978). In cats, longterm decreases in spontaneous neuronal activity in the caudate nucleus occur following administration of am-

\footnotetext{
${ }^{1}$ This work was supported by United States Public Health Service Grants HD 05958 and HD 07032.

${ }^{2}$ To whom correspondence should be addressed.
}

phetamine (Levine et al., 1980). In addition, this compound temporarily blocks the ability of nigral neurons to respond to their monosynaptic and polysynaptic inputs (Fisher et al., 1982). As the effects of the temporary blockade wear off, stimulation of inputs evokes excitatory responses that are almost never found prior to amphetamine administration (Fisher et al., 1982).

These studies have not provided any information concerning the effects of amphetamine on the processing of discrete afferent information by caudate neurons or on the ability of amphetamine to modulate polarization levels of the cell membrane. Therefore, the present study was undertaken to assess the effects of amphetamine on the intracellular responses of caudate neurons to activation of their major afferents (cortex, intralaminar thalamus, and substantia nigra) (Dray, 1980). The results demonstrate that both drug-related alterations in resting membrane potentials and evoked postsynaptic potentials (PSPs) occur and that these effects are independent of the peripheral autonomic effects induced by amphetamine.

\section{Materials and Methods}

Animul preparation and surgery. Intracellular recordings were obtained from caudate neurons in 21 adult cats of both sexes. Initial surgical manipulations for preparing animals for recording have been detailed elsewhere (Buchwald et al., 1973). The animal was first anesthetized with Brevital Sodium. The femoral vein of one leg 
was cannulated to allow drug administration. The femoral artery of the other leg was cannulated in some animals $(n=10)$ to allow monitoring of blood pressure. Blood pressure was recorded via a standard Statham cardiovascular pressure transducer and displayed on a polygraph. Heart rate was monitored throughout the experiment. Rectal temperature was monitored and maintained at $37^{\circ} \mathrm{C}$. Craniotomies and dural retraction were performed for placement of stimulating and recording electrodes. After these procedures had been completed, the animals were artifically respired and paralyzed by intravenous injections of gallamine triethiodide. All wound margins and pressure points were infused with local anesthetics, which were periodically readministered throughout the course of the experiment.

The cortex immediately overlying the caudate was aspirated. The recording electrode was then placed into the caudate under visual inspection and the defect filled with Sylgard and warm paraffin. Intracellular recordings were made with $1.6 \mathrm{M}$ potassium citrate-filled glass micropipettes. Chlorided electrodes and ground leads were used to help prevent fluctuations or drift of the baseline level. Signals were amplified by a directly coupled amplifier, monitored on an oscilloscope, and recorded on FM tape for subsequent analysis.

Concentric bipolar stimulating electrodes $(0.5 \mathrm{~mm} \mathrm{ex}-$ posed tips) were stereotaxically implanted in the substantia nigra and in the intralaminar thalamus (center median and parafascicular nuclei). Bipolar stainless steel wires, insulated except at the tips, were implanted in medial pericruciate cortex.

After a neuron was impaled, its responses to stimulation of cortex, thalamus, and substantia nigra were tested (10 to 15 trials per stimulation site, $0.5 \mathrm{~Hz}, 0.1$ to 0.5 msec pulse duration, 2 to $12 \mathrm{~V}$ ). $d$-Amphetamine sulfate (either low dose, $0.1 \mathrm{mg} / \mathrm{kg}$ of body weight, or high dose, $0.5 \mathrm{mg} / \mathrm{kg}$ of body weight, $5 \mathrm{mg} / \mathrm{ml}$ of saline vehicle) was then administered intravenously. Approximately 3 to 5 min following amphetamine injection, the impaled cell was again tested for responses to afferent stimulation. These tests were repeated every $10 \mathrm{~min}$ for up to $1 \mathrm{hr}$ after the injection or until the cell was lost or became injured. To minimize interactions between the effects of successive injections, at least $2 \mathrm{hr}$ were allowed to elapse between testing of cells. In several animals the first few recorded cells were tested for effects of saline injection $(0.9 \% \mathrm{NaCl}$, i.v., in equal volume to low or high dose of amphetamine injections). The responses of these cells were tested in the same manner as cells after amphetamine injection.

The most frequently occurring evoked PSP responses of caudate neurons when their inputs are stimulated are depolarizations followed by hyperpolarizations (Buchwald et al., 1973). For the present experiments, the depolarization evoked by the stimulus was considered to be an excitatory postsynaptic potential (EPSP) while the hyperpolarization was considered an inhibitory postsynaptic potential (IPSP). The PSP responses of each neuron were averaged on a PDP-12 computer to obtain a mean and standard deviation for at least 10 trials of each evoked response. These averaged responses were then used to obtain measures of latency to EPSP onset, EPSP amplitude, EPSP duration, IPSP amplitude, and IPSP duration. Data obtained prior to amphetamine administration were used to compute baseline values for each neuron. For postdrug comparison, values were calculated as percentage differences from baseline. For each index, at each time period postdrug, the mean postdrug value for each cell was subtracted from the mean baseline value for that cell, divided by the baseline valuc, and multiplied by 100 . The result showed both percentage change from baseline and direction of change (increase or decrease).

At the conclusion of the experiment the animal received an overdose of barbiturate. Marking lesions were produced at all subcortical stimulation sites and the last recording site. The cat was then perfused with saline followed by formalin. Brains were removed, sectioned, and stained with cresyl violet for verification of stimulation and recording sites.

\section{Results}

Intracellular recordings were obtained from 37 neurons located in the head of the caudate nucleus. Of these, 23 were tested with $0.5 \mathrm{mg} / \mathrm{kg}$ of amphetamine, 7 with 0.1 $\mathrm{mg} / \mathrm{kg}$ of amphetamine, and 7 with saline.

Alleration in resting membrane potentials. High doses of amphetamine produced a reversible depolarization of the cell membrane in 18 of 23 tested cells $(78 \%)$. This response began approximately $1 \mathrm{~min}$ after injection (mean latency $\pm 1 \mathrm{SD}=71 \pm 26 \mathrm{sec}$ ). The average response amplitude was $18 \pm 12 \mathrm{mV}$, and the average response duration was $172 \pm 47 \mathrm{sec}$. During the depolarization, all tested cells remained responsive to their inputs but the amplitude of the EPSP decreased while the amplitude of the IPSP increased or remained unchanged. These depolarizations were also associated with a decrease in action potential generation (about $30 \%$ ). Figure 1 illustrates a typical reversible depolarization in response to amphetamine. Membrane resistance changes were calculated for eight cells which showed the depolarizing response. No consistent resistance changes occurred during the amphetamine-induced depolarizations (four cells showed an increase, two decreased, and two did not change)

Six additional neurons showed a much larger (40 to 60 $\mathrm{mV}$ ) depolarization in response to the amphetamine injection. During this depolarization total blockade of evoked PSP responses occurred. Since these cells never repolarized, it is likely that they were damaged or the recording electrode was no longer inside the cell. Data from these cells were not included in the present analysis.

In all animals, autonomic effects consisting of blood pressure elevation, heart rate increases, and pupil dilation occurred after each injection of amphetamine. The reversible membrane depolarization did not appear to be associated with the amphetamine-induced increase in blood pressure. Membrane depolarization was not coincident with the blood pressure increases. Latency to increase in blood pressure was shorter than the latency to the depolarization (mean latency $26 \pm 10 \mathrm{sec}$ ). The blood pressure increase also had a longer duration (mean duration $253 \pm 75 \mathrm{sec}$ ) than the membrane depolarization. In another effort to dissociate central effects of amphetamine from peripheral autonomic effects, we ad- 


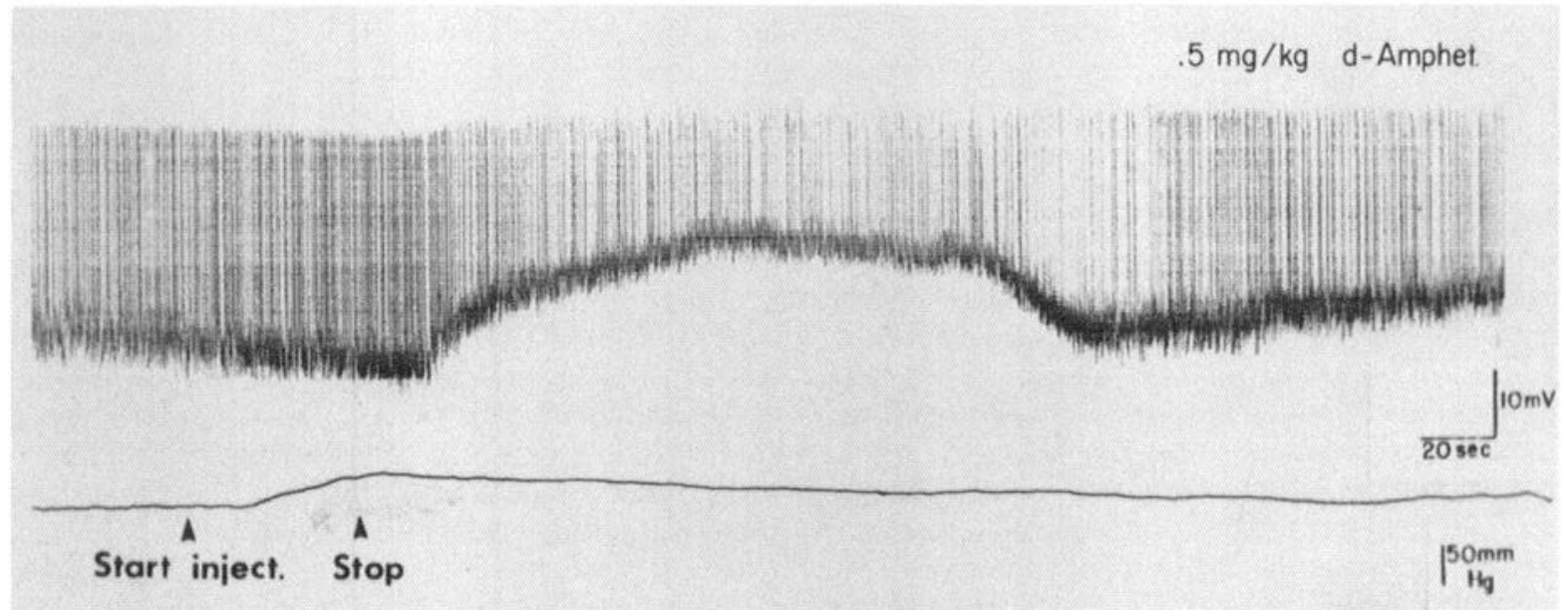

Figure 1. Membrane potential response to intravenous injection of amphetamine $(0.5 \mathrm{mg} / \mathrm{kg})$. The upper trace shows the response of a single caudate neuron. The lower trace shows the change in blood pressure associated with amphetamine injection. The neuronal response begins $62 \mathrm{sec}$ after amphetamine administration and lasts $162 \mathrm{sec}$. The rise in blood pressure associated with drug administration has a latency of $18 \mathrm{sec}$ and lasts $285 \mathrm{sec}$.

ministered quaternary amphetamine (a compound which produces the peripheral autonomic effects of amphetamine, but because of its quaternary structure probably does not cross the blood-brain barrier) intravenously to four cats. Ten cells were tested for the effects of quaternary amphetamine in the same manner as described for amphetamine or saline, and they were held for comparable periods of time. Quaternary amphetamine was injected at several dose levels ranging from 0.125 to $0.5 \mathrm{mg} / \mathrm{kg}$. Injections caused large blood pressure changes (approximately $50 \mathrm{mmHg}$ increase) but no significant changes in resting membrane potentials. The average latency and duration of these increases in blood pressure were $26 \pm 13$ and $88 \pm 35 \mathrm{sec}$, respectively.

There were additional indications that the membrane depolarization was not related to the peripheral autonomic effects of amphetamine. For example, no correlation was found between the number of injections a cat received, the position of the cell in the injection sequence, and the presence, absence, or magnitude of the depolarization response. Reduction of the magnitude of changes in the peripheral blood pressure and other autonomic effects occurred in all cats after the first injection of amphetamine. No reduction was seen in the magnitude of the effects of the amphetamine on membrane potentials or on PSP responses in caudate neurons, further suggesting a dissociation between peripheral and central effects of the drug. Finally, effects on the resting membrane potential were not observed in any of the seven cells tested under the low dose condition. This dose did produce increases in blood pressure and heart rate as well as pupillary dilation.

Alterations in evoked synaptic potentials. All caudate cells tested responded to stimulation of pericruciate cortex, substantia nigra, or thalamus with an initial EPSP followed by a longer duration IPSP (EPSP-IPSP sequence). No significant changes in EPSP latency, EPSP duration, or IPSP duration were induced by amphetamine at either dose level (Table I).

The major effect of amphetamine was to produce statistically significant and long-lasting $(>30 \mathrm{~min})$ increases in the amplitudes of both inhibitory and excitatory components of evoked PSP responses. Overall this effect was more marked for the inhibitory than for the excitatory component of the EPSP-IPSP sequence and occurred more frequently for EPSP-IPSP sequences evoked by cortical than by either thalamic or nigral stimulation. Figure 2 illustrates the response of one caudate neuron to stimulation of cortex before and up to $45 \mathrm{~min}$ after the administration of amphetamine at $0.5 \mathrm{mg} / \mathrm{kg}$. Both the amplitude of the EPSP and the IPSP increased markedly. Maximum increases in EPSP amplitude $(+66 \%)$ occurred 30 min postinjection while the maximum increase in IPSP amplitude $(+125 \%)$ occurred 10 min postinjection. For the duration of the test period, the background noise level, spike height, and frequency remained relatively unchanged, suggesting that the cell was not damaged during the testing sequence.

Consistent changes in amplitude of responses did not occur after saline injection or injection of quaternary amphetamine. Figure $3, A$ and $B$, shows caudate neuron responses to cortical stimulation before and after administration of saline and quaternary amphetamine, respectively. Maximum changes in the amplitude of either the EPSP or IPSP were small $(<7 \%)$ and varied in direction. After injections of quaternary amphetamine, maximum changes in amplitude of PSPs were also small and varied in direction. These negligible changes were contrasted by the consistent increases in amplitude observed after amphetamine.

Figures 4 and 5 summarize the time course of the average percentage changes in PSP amplitude for all cells tested under each condition. The amplitude of the EPSP evoked by cortical stimulation increased more than the amplitude of EPSPs evoked by stimulation of the other sites. This effect was most consistently observed at the high dose level and in later time periods postinjection. While some enhancement of nigral and thalamus-evoked EPSPs did occur, these effects were not as large and consistent as those seen after cortical stimulation. To provide a statistical assessment of induced PSP amplitude changes, data for each cell were 
TABLE I

Percentage change from predrug baseline averaged 3 to 30 min postinjection

\begin{tabular}{|c|c|c|c|c|c|}
\hline & $\begin{array}{c}\text { Pre-drug } \\
\text { Baseline } \\
\text { Parameters }^{a}\end{array}$ & $0.1 \mathrm{mg} / \mathrm{kg}$ & $0.5 \mathrm{mg} / \mathrm{kg}$ & Saline & $\begin{array}{l}\text { Quaternary } \\
\text { Amphetamine }\end{array}$ \\
\hline & SE & $\mathrm{SE}$ & $\mathrm{SE}$ & $\mathrm{SE}$ & SE \\
\hline \multicolumn{6}{|c|}{$\begin{array}{l}\text { Excitatory potential } \\
\text { amplitude }\end{array}$} \\
\hline $\mathrm{CX}^{b}$ & $10.2 \mathrm{mV} \pm 1.8$ & $25.8 \pm 7.9$ & $63.5 \pm 20.6$ & $6.9 \pm 5.6$ & $-3.0 \pm 8.3$ \\
\hline $\mathrm{SN}$ & $6.7 \pm 1.1$ & $11.3 \pm 24.6$ & $41.7 \pm 18.2$ & $36.9 \pm 11.2$ & $27.8 \pm 26.2$ \\
\hline Thal & $8.3 \pm 1.7$ & $13.4 \pm 10.0$ & $37.2 \pm 20.1$ & $10.7 \pm 16.0$ & $-16.8 \pm 12.3$ \\
\hline \multicolumn{6}{|c|}{$\begin{array}{l}\text { Inhibitory potential am- } \\
\text { plitude }\end{array}$} \\
\hline $\mathrm{CX}$ & $10.0 \mathrm{mV} \pm 2.0$ & $91.3 \pm 23.7$ & $83.4 \pm 33.8$ & $6.7 \pm 3.6$ & $-19.5 \pm 1.9$ \\
\hline $\mathrm{SN}$ & $11.2 \pm 4.6$ & $57.3 \pm 15.9$ & $51.6 \pm 18.5$ & $-5.4 \pm 29.7$ & $-21.9 \pm 9.8$ \\
\hline Thal & $10.1 \pm 1.9$ & $19.1 \pm 15.4$ & $72.9 \pm 17.9$ & $20.6 \pm 17.1$ & $-6.4 \pm 14.9$ \\
\hline \multicolumn{6}{|c|}{$\begin{array}{l}\text { Excitatory potential la- } \\
\text { tency }\end{array}$} \\
\hline $\mathrm{CX}$ & $9.0 \mathrm{msec} \pm .3$ & $-2.9 \pm 6.7$ & $-3.1 \pm 2.1$ & $-7.6 \pm 6.7$ & $-2.7 \pm 9.1$ \\
\hline SN & $8.9 \pm 1.1$ & $0.2 \pm 8.5$ & $5.5 \pm 3.1$ & $7.2 \pm 3.0$ & $6.3 \pm 5.1$ \\
\hline Thal & $10.6 \pm 2.7$ & $6.3 \pm 9.6$ & $8.5 \pm 2.3$ & $-17.5 \pm 3.3$ & $-0.5 \pm 1.3$ \\
\hline \multicolumn{6}{|c|}{$\begin{array}{l}\text { Excitatory potential du- } \\
\text { ration }\end{array}$} \\
\hline $\mathrm{CX}$ & $43.8 \mathrm{msec} \pm 6.0$ & $-8.9 \pm 5.1$ & $-2.7 \pm 4.5$ & $-1.2 \pm 1.1$ & $3.6 \pm 5.3$ \\
\hline SN & $40.7 \pm 6.4$ & $-6.6 \pm 2.7$ & $0.5 \pm 5.3$ & $-6.6 \pm 3.0$ & $4.2 \pm 11.4$ \\
\hline Thal & $45.0 \pm 4.6$ & $8.4 \pm 2.6$ & $1.8 \pm 10.5$ & $4.1 \pm 5.9$ & $4.6 \pm 11.2$ \\
\hline \multicolumn{6}{|c|}{$\begin{array}{l}\text { Inhibitory potential du- } \\
\text { ration }\end{array}$} \\
\hline $\mathrm{CX}$ & $197.1 \mathrm{msec} \pm 14.4$ & $3.3 \pm 1.3$ & $2.4 \pm 1.2$ & $0.2 \pm 1.0$ & $-3.9 \pm 1.2$ \\
\hline $\mathrm{SN}$ & $186.7 \pm 25.2$ & $7.3 \pm 5.1$ & $3.0 \pm 2.5$ & $-2.1 \pm 3.7$ & $-8.4 \pm 2.5$ \\
\hline Thal & $170.8 \pm 25.5$ & $-5.4 \pm 4.1$ & $9.0 \pm 2.9$ & $-0.1 \pm 3.4$ & $-1.7 \pm 1.9$ \\
\hline
\end{tabular}

${ }^{a}$ Predrug measurements were computed from all 47 cells tested. Postdrug measurement was computed by averaging data from all cells in each group: 7 at $0.1 \mathrm{mg} / \mathrm{kg}, 23$ at $0.5 \mathrm{mg} / \mathrm{kg}, 7$ saline, and 10 quaternary amphetamine.

${ }^{b} \mathrm{CX}$, cortex; SN, substantia nigra; Thal, thalamus.

averaged across the postinjection time period (Table I). Differences among group means were assessed with analyses of variance and standard post hoc comparisons. For the cortical response, there were statistically significant $(p<0.05)$ differences in the mean percentage changes in EPSP amplitude between the high dose and each other condition. These relationships did not reach statistical significance for EPSPs evoked by stimulation of the other sites.

The greatest magnitude and most consistent increases in amplitude occurred for the IPSPs (Fig. 5). This effect was seen at both low and high doses of amphetamine and did not occur with either injections of saline or quaternary amphetamine. As was the case with the enhanced amplitude of EPSPs, the increases in IPSP amplitude were greatest for responses evoked from cortex. Most effects were present by the first test postinjection and tended to increase in amplitude over time after the injection. Consistent and large changes in responses evoked after saline or quaternary amphetamine did not occur. Statistical assessment (Table I) indicated that for the cortical response, significant differences $(p<0.05)$ between mean percentage changes in IPSP amplitude from baseline were found between low dose and saline, low dose and quaternary amphetamine, high dose and saline, and high dose and quaternary amphetamine. No significant differences were found between high dose and low dose conditions or between saline and quaternary amphetamine conditions. These same relationships were observed for responses to nigral stimulation. For the thalamic response, significant differences $(p<0.05)$ were found between high dose and all other conditions. There were no other significant differences among these groups.

There were also no relationships between the number of a particular cell in an injection sequence and the presence, absence, or magnitude of the effect on EPSP or IPSP response components. Although at the high dose of amphetamine most cells displayed both effects, there were no apparent relationships between the magnitude of the depolarization response and the magnitude of effect on postsynaptic potentials.

Two additional cells were tested for the effects of both quaternary amphetamine and amphetamine. In these cells, quaternary amphetamine was administered first, and the cell was tested for $60 \mathrm{~min}$. Then a high dose of amphetamine was administered, and the cells were tested for another $45 \mathrm{~min}$. In both cells, the quaternary amphetamine caused a large blood pressure increase, but no consistent changes were observed in membrane polarization level or PSP responses. Amphetamine also produced a large blood pressure increase in each cell. However, in both cells, amphetamine caused initial reversible 
SINGLE RESPONSES
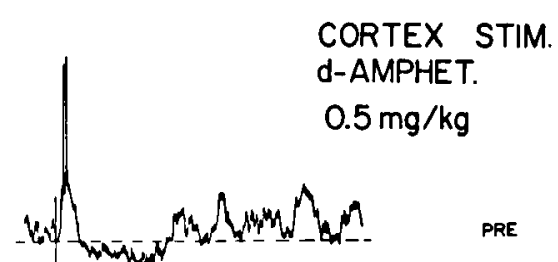

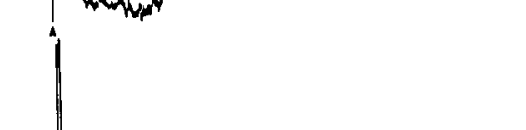
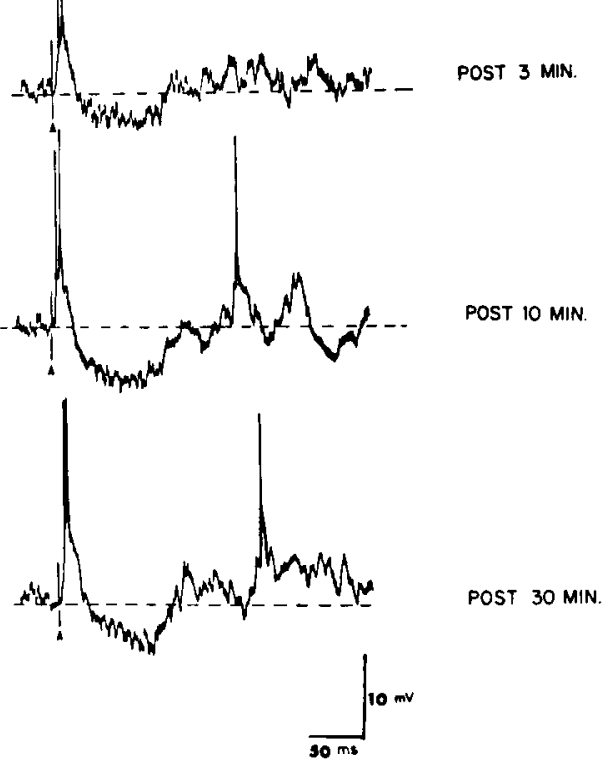

AVERAGE 10 RESPONSES
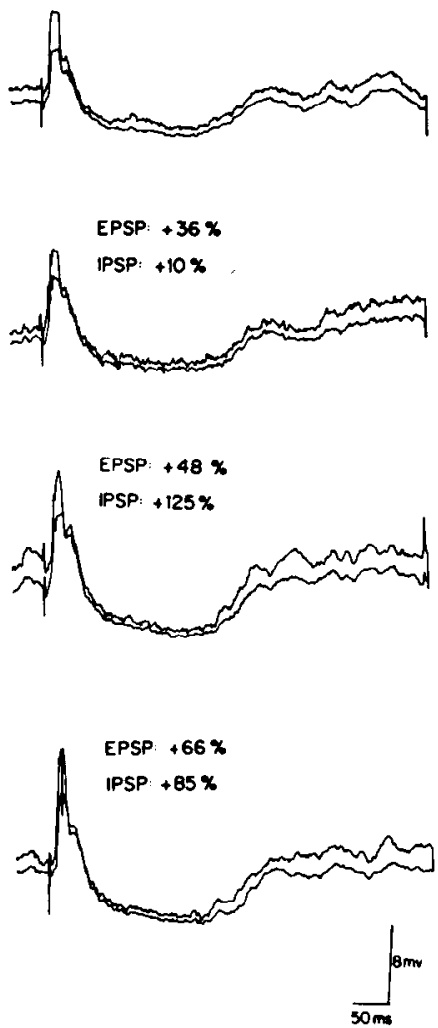

Figure 2. Effects of high dose $d$-amphetamine on synaptic potentials recorded from a caudate neuron evoked by stimulation of pericruciate cortex. The left column shows single responses of the neuron prior to drug administration and 3,10 , and 30 min postinjection. The dotted line indicates resting membrane level. Arrowheads indicate stimulus onset. The right column shows the average of 10 single responses with the spikes filtered off. The bottom trace of each pair represents the average response. The distance between the two traces represents the standard deviation. Percentage changes in EPSP and IPSP amplitudes from predrug baseline are noted for all averages postinjection.

depolarizations of the cell membrane followed by increases in the amplitudes of both evoked EPSPs and IPSPs.

\section{Discussion}

The present research revealed two temporally distinct effects of amphetamine on the intracellularly recorded activity of caudate neurons. First, high doses of amphetamine produced a reversible depolarization of the resting membrane potential. Second, amphetamine produced increases in the amplitude of evoked PSPs in caudate neurons. Neither of these effects appeared to be related to the peripheral sympathomimetic actions of amphetamine.

Peripheral autonomic responses of amphetamine. Intravenous amphetamine administration produced "peripheral" autonomic effects that were probably due to systemic release of adrenal medullary catecholamines as well as neural mediation in the brain or autonomic ganglia (Korner, 1981). These effects consisted of blood pressure increases, heart rate increases, and pupillary dilation. In the present experiments it did not appear that the neurophysiological alterations were mediated by these peripheral autonomic changes since latency and duration of blood pressure increases did not co-vary with latency and duration of the neurophysiological effects. Blood pressure increases occurred with shorter latencies and were of longer duration than the observed reversible depolarization. Furthermore, if the depolarization response observed was simply a result of alterations in blood pressure, then it is likely that each time a blood pressure increase occurred a depolarization would also occur. This was clearly not the case because a number of cells showed a large depolarization but only small blood pressure increases occurred, whereas other neurons were recorded with no depolarization but large blood pressure 


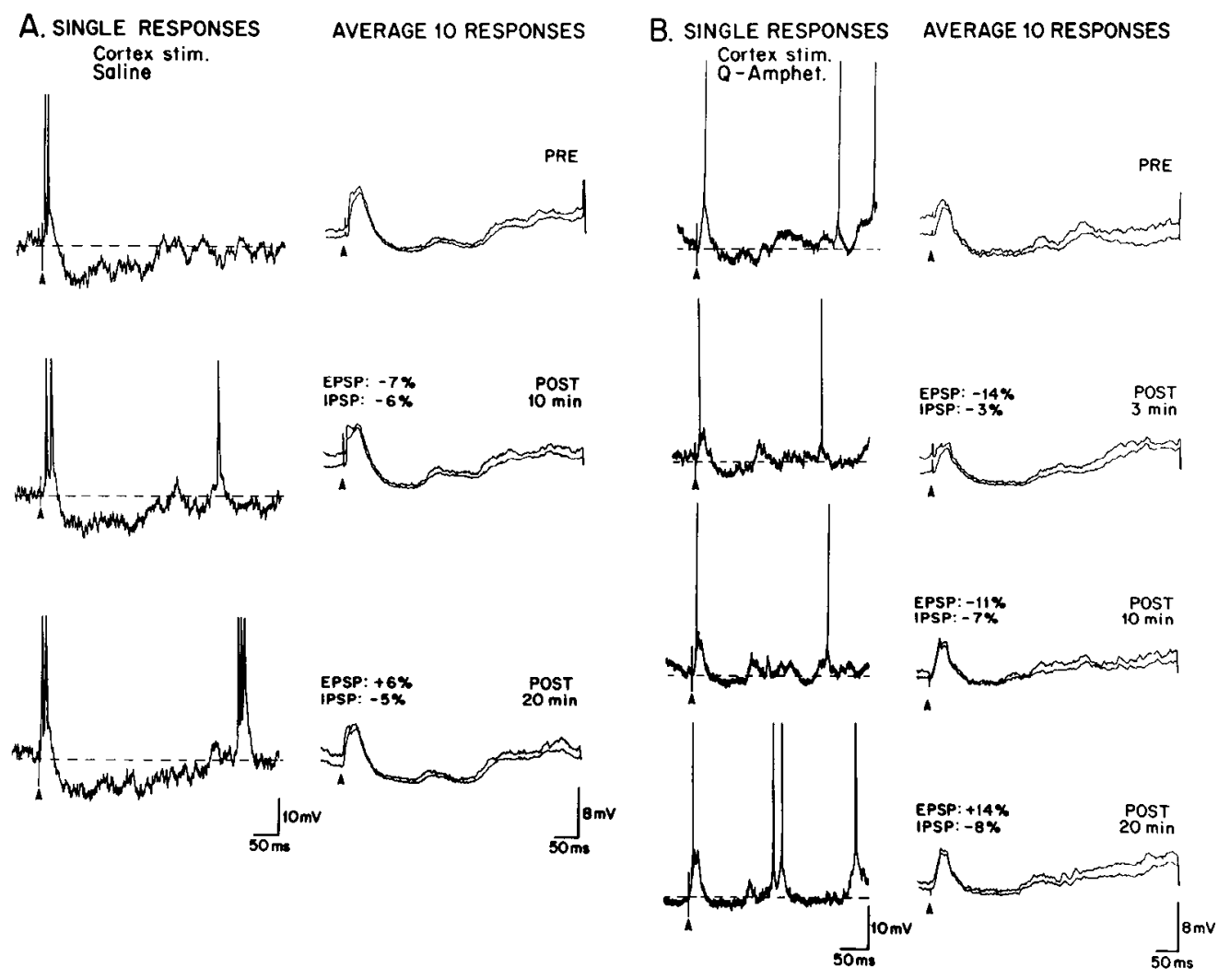

Figure 3. Effects of saline $(A)$ and quaternary amphetamine $(B)$ injections on synaptic potentials recorded from a caudate neuron evoked by pericruciate cortex stimulation. See Figure 2 for description. Note negligible changes in EPSP and IPSP amplitudes in cells held for times comparable to those for amphetamine-tested cells.

increases. Additionally, injection of quaternary amphetamine, a compound which increases blood pressure via direct action on the sympathetic system but probably does not cross the blood-brain barrier, did not cause any depolarization responses or consistent alteration in evoked PSPs.

It is possible that some of the long-term increases in PSP amplitude were related to damage to the neurons during long-lasting impalements. This, however, appears unlikely since consistent increases in PSP amplitude did not occur in neurons held for long periods of time $(>30$ $\mathrm{min}$ ) after either saline or quaternary amphetamine injection.

Amphetamine-induced reversible depolarizations. There are a number of points that argue for the possibility that the reversible depolarization is related to amphetamine-induced release of DA from the endings of nigrostriatal neurons in the caudate nucleus. Amphetamine is currently believed to exert its central effects by enhancing release and inhibiting reuptake of DA (Dray, 1980). Thus, amphetamine should operate by increasing the amount of available DA at synaptic sites. There are similarities in the action of DA and amphetamine on striatal neurons. First, in extracellular recording experiments, amphetamine has been shown to mimic the effects of DA or DA agonists on caudate neuronal spontaneous firing rates (Feltz and DeChamplain, 1973; Groves et al., 1978). Second, in a recent preliminary study using voltammetric measurements of striatal DA release, the onset time of amphetamine-induced increase in dopamine release was coincident with the onset time for the reversible depolarization reported in the present results (Howard-Butcher et al., 1983). Finally, iontophoretic application of DA or DA agonists produces initial depolarizations associated with reduced frequency of action potential generation in intracellulary recorded caudate neurons (Bernardi et al., 1978; Herrling and Hull, 1980). These effects can be blocked or attenuated by application of DA antagonists (Herrling and Hull, 1980). At the present time the synaptic mechanisms underlying this depolarization associated with decreased action potential generation are unclear. Herrling and Hull (1980) indicate that this effect, if it is specific to DA at all, might be mediated by differential actions of DA on caudate neurons. In their results, iontophoretic application of DA distant from the soma produced slow depolarizations associated with a reduction in frequency of action potential generation. In contrast, application of DA close to the soma produced both membrane hyperpolarizations or biphasic effects where the hyperpolarization preceded the depolarization. They proposed that DA hyperpolarizes the axon hillock which would reduce the ability of the neuron to generate action potentials. In addition, DA depolarizes the dendrites. When DA is applied at a distance from the soma only the depolarization is observed, and because of its larger amplitude it masks the hyperpolarization which occurs when enough DA reaches the initial segments and which produces a reduction in 


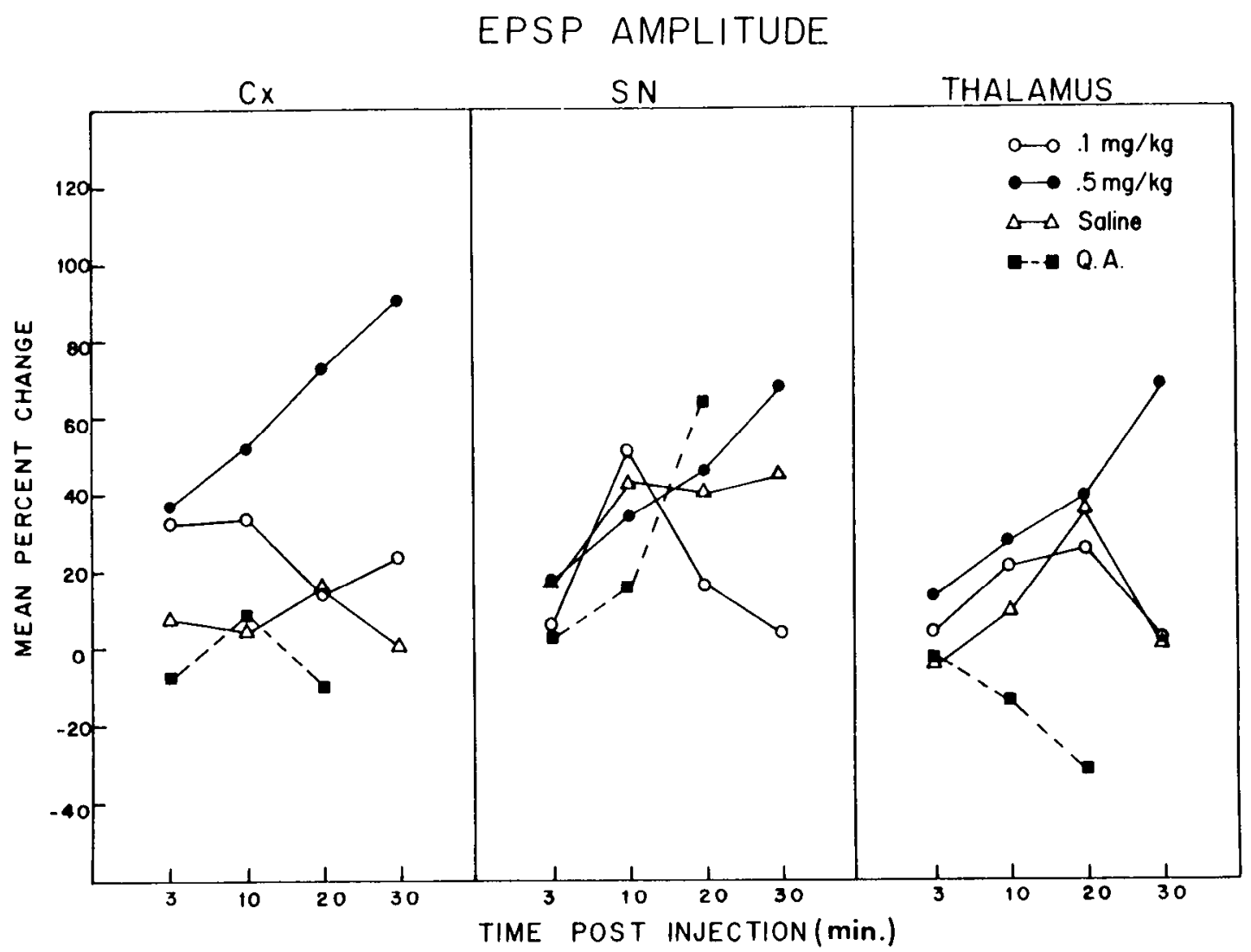

Figure 4. Mean percentage changes in EPSP amplitudes of stimulation evoked PSPs in caudate neurons. Only cortical $(C x)$ evoked EPSPs show a significant increase in amplitude (as compared to predrug response amplitudes), and this effect is only evident with administration of high dose amphetamine. $S N$, substantia nigra.

firing rate. When DA is applied close to the soma, the initial segment is reached fast enough so that the hyperpolarization can be measured before it is masked by the slow depolarization. In conjunction with the present data, this hypothesis would imply that most amphetamine-induced DA release occurs at synapses on the dendrites and/or spines of caudate neurons, since amphetamine-induced hyperpolarizations of the membrane potential were not observed.

It is attractive to single out the effects of amphetamine on DA release and its reuptake as being related to the present findings, but we recognize that a variety of factors may possibly have contributed to the outcome of this experiment. There are close and complex interactions between the other putative neurotransmitter systems in the caudate nucleus that could be affected by the amphetamine administration (Dray, 1980). In addition, there is recent evidence that DA may exert its actions presynaptically on dendrites and axons of dopaminergic neurons (Groves et al., 1979) which would interact with any of its postsynaptic effects.

Amphetamine-induced increases in PSP amplitude. In addition to the reversible depolarization, amphetamine administration resulted in increased amplitude of evoked IPSPs and, to a lesser extent, FPSPs elicited by stimulation of striatal afferents. PSP changes were always long-lasting and more pronounced after high dosages than low dosages of amphetamine. Such alterations sug- gest that amphetamine-related changes in neurotransmission alter the mechanisms responsible for handling discrete information within the caudate. Furthermore, they suggest that increased DA release may have a longlasting facilitatory effect on either excitatory or inhibitory synaptic transmission. This finding may also relate to the long-lasting changes in caudate neuronal firing patterns seen extracellularly following amphetamine administration (Levine et al., 1980). It is possible that the long-lasting decreases in spontaneous firing pattern of caudate neurons are the final consequences of the increases in amplitude of evoked PSP responses.

As can be seen in Figures 4 and 5 and Table I, the amphetamine-induced increases in evoked PSP amplitude were greatest in magnitude and duration after cortical activation. It is presently unclear why the effect of amphetamine occurs predominantly on the cortically elicited EPSP-IPSP sequence. Anatomical and physiological evidence suggests that the cortex provides a more dominant input to caudate neurons than either substantia nigra or thalamus (Kemp and Powell, 1971; Hull et al., 1973). Since such input has the greatest effect on caudate neurons, it might be more susceptible to altered neurochemical transmission induced by amphetamine. The larger increase in amplitude of evoked cortical PSPs might be reflective of the distribution of the corticostriate endings on caudate neurons. There is evidence that such endings occur predominantly on spines (Kemp and Pow- 


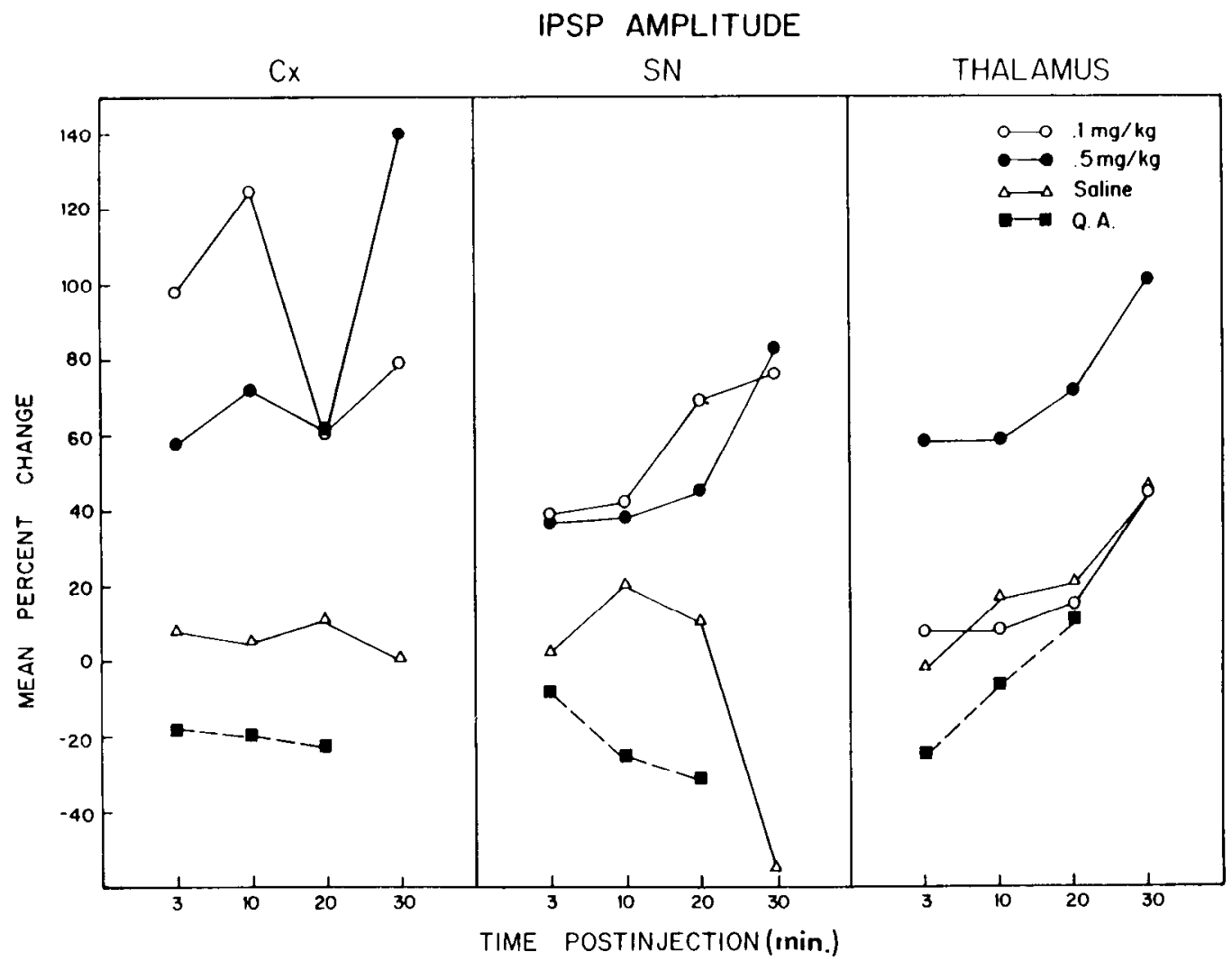

Figure 5. Mean percentage changes in the amplitudes of inhibitory components of stimulationevoked PSPs in caudate neurons. Cortical $(C x)$ and, to a lesser extent, nigral $(S N)$ evoked IPSPs increase in amplitude following both high and low doses of $d$-amphetamine. The inhibitory component of EPSP-IPSP sequences evoked by thalamic stimulation showed increases in amplitudes only under high dose conditions.

ell, 1971). The effects of cortical inputs may be amplified by the amphetamine-induced DA release as they are transmitted from the spine to the soma. There are recent data indicating that nigrostriate dopaminergic endings may have selective presynaptic influences on corticostriate endings (Schwarcz et al., 1978). These influences should provide an additional site of interaction between DA and corticostriate input. Finally, since the systemically administered amphetamine also affects the neurophysiological properties of dopaminergic (Bunney and Aghajanian, 1973) and nondopaminergic nigral neurons (Groves et al., 1978), complex interactions between nigrostriatal and corticostriatal afferents may also be occurring.

It is not surprising that the amplitudes of both EPSPs and IPSPs are enhanced by the amphetamine. It is generally accepted that striatal inputs produce initially excitatory responses in caudate neurons (Buchwald et al., 1973; Dray, 1980; Vandermaelen and Kitai, 1980). Thus, any facilitatory effect on synaptic transmission should enhance this EPSP. If, as we have hypothesized (Hull et al., 1973; Schneider et al., 1983), the subsequent IPSP is due to local inhibitory interaction among neighboring striatal neurons, then it would be expected that the IPSP should also increase in amplitude. Larger amplitude EPSPs would probably generate more action potentials which would increase the magnitude of the locally generated inhibition.
This view of an intrinsic origin of the IPSP of the EPSP-IPSP sequence observed in caudate neurons when their inputs are activated has recently been questioned. The results of a series of experiments (Wilson et al., $1982,1983 \mathrm{a}, \mathrm{b})$ have indicated that the long-duration IPSP may not be a true IPSP but rather a disfacilitation arising from inhibition of tonically active striatal inputs from the cerebral cortex. If this were the case, the mechanism for the amphetamine-induced potentiation of the IPSP would have to involve amphetamine's affecting cortical neurons directly. Since there is anatomical evidence for a catecholaminergic innervation of the cerebral cortex (Moore and Bloom, 1978, 1979), it is possible that amphetamine-induced release of dopamine or norepinephrine in the cortex facilitates the effects of the cortical stimulus on cortical neurons, thus enhancing both the activation of cortical neurons themselves and the subsequent inhibition of cortical neurons (Wilson et al., $1983 \mathrm{~b})$. By this explanation at least two mechanisms could be responsible for the enhanced EPSP evoked in caudate neurons after amphetamine administration - the direct effect of DA on these neurons and an indirect effect mediated by cortical neurons. The enhanced hyperpolarization would be related to increasing inhibition at the cortex and a larger magnitude disfacilitation of caudate neurons.

Regardless of the origin of the EPSP or IPSP, the results of the present experiment indicate that amphet- 
amine is capable of modulating the ability of striatal neurons to process discrete information by potentiating the amplitude of PSPs evoked in striatal neurons. Since the major action of amphetamine is to enhance catecholamine release and block its reuptake, it is conceivable that the increased quantities of these substances around synapses serve to increase the ability of neurons to respond to afferent impulses.

\section{References}

Bernardi, G., M. G. Marciani, C. Morocutti, F. Pavone, and P. Stantione (1978) The action of dopamine on rat caudate nucleus neurons intracellularly recorded. Neurosci. Lett. 8: 235-240.

Biggio, G., M. Casa, M. G. Corda, C. Dibello, and G. L. Gessa (1978) Stimulation of dopamine synthesis in caudate nucleus by intrastriatal enkephalins and antagonism by naloxone. Science 200: 50-52.

Buchwald, N. A., D. D. Price, L. Vernon, and C. D. Hull (1973) Caudate intracellular responses to thalamic and cortical inputs. Exp. Neurol. 38: 311 323.

Bunney, B. S., and G. K. Aghajanian (1973) Electrophysiological effects of amphetamine on dopaminergic neurons. In Frontiers in Catecholamine Research, E. Usdin and S. H. Snyder, eds., pp. 957-962, Pergamon Press, London.

Bunney, B. S., J. R. Walters, R. H. Roth, and G. K. Aghajanian (1973) Dopaminergic neurons: Effects of antipsychotic drugs and amphetamine on single-cell activity. J. Pharmacol. Ther. 185: 560-571.

Dray, A. (1980) The physiology and pharmacology of the mammalian basal ganglia. Neurobiology 14: 221-336.

Feltz, P., and J. DeChamplain (1973) The postsynaptic effect of amphetamine on striatal dopamine-sensitive neurons. In Frontiers in Catecholamine Research, E. Usdin and S. H. Snyder, eds., pp. 951-956, Pergamon Press, London.

Fisher, R. S., M. S. Levine, C. D. Hull, and N. A. Ruchwald (1982) Amphetamine alters evoked responses of nigral neurons in kittens and adult cats. Brain Res. 273: 415-427.

Groves, P. M., and G. V. Rebec (1976) Biochemistry and behavior: Some central actions of amphetamine and antipsychotic drugs. Annu. Rev. Psychol. 27: 91-127.

Groves, P. M., G. V. Rebec, and D. S. Segal (1974) The action of $d$-amphetamine on spontaneous activity in the caudate nucleus and reticular formation of the rat. Behav. Biol. 11: $33-47$.

Groves, P. M., S. J. Young, and C. J. Wilson (1978) Nigrostrial relations and the mechanisms of action of amphetamine. In Cholinergic-Monoaminergic Interactions in the Brain, pp. 177-210, Academic Press, Inc., New York.

Groves, P. M., D. A. Staunton, C. J. Wilson, and S. J. Young (1979) Sites of action of amphetamine intrinsic to catecholaminergic nuclei: Catecholaminergic presynaptic dendrites and axons. Prog. Neuropsychopharmacol. 3: 315-335.

Ilerrling, P. L., and C. D. Hull (1980) Iontophoretically applied dopamine depolarizes and hyperpolarizes the membrane of cat caudate neurons. Brain Res. 192: 441-462.

Howard-Butcher, S., R. F. Lane, and C. D. Blaha (1983) Effects of PCP on DA release using in vivo voltammetry. In Phencyclidine and Related Arylcyclohexylamines. Present and Future Applications, E. Kamenka, E. F. Domino, and P. Geneste, eds., pp. 471-484, NPP Books, Ann Arbor.

Hull, C. D., G. Bernardi, D. D. Price, and N. A. Buchwald (1973) Intracellular responses of caudate neurons to temporally and spatially combined stimuli. Exp. Neurol. 38: 324336 .

Kemp, J. M., and T. P. S. Powell (1971) The termination of fibers from the cortex and thalamus upon dendritic spines in the caudate nucleus. A study with the Golgi method. Philos. Trans. R. Soc. Lond. Biol. 262: 429-439.

Korner, P. I. (1981) The central nervous system and its operation in cardiovascular control. Clin. Exp. Hypertension 3: $343-368$.

Levine, M. S., C. D. Hull, E. Garcia-Rill, L. Erinoff, and A. Heller (1980) Longterm decreases in spontaneous firing of caudate neurons induced by amphetamine in cats. Brain Res. 191: 263-268.

Moore, R. Y., and F. E. Bloom (1978) Central catecholamine neuron systems: Anatomy and physiology of the dopamine systems. Annu. Rev. Neurosci. 1: 129-169.

Moore, R. Y., and F. E. Bloom (1979) Central catecholamine neuron systems: Anatomy and physiology of the norepinephrine and epinephrine systems. Annu. Rev. Neurosci. 2: 113168.

Rebec, C. V., and P. M. Groves (1975) Differential effects of the optical isomers of amphetamine on neuronal activity in the reticular formation and caudate nucleus of the rat. Brain Res. 83: 301-318.

Schneider, J. S., J. S. Wilson, C. D. Hull, and N. A. Buchwald (1983) Intracellular responses of caudate neurons to stimulation of cortex and substantia nigra following large thalamic lesions. Brain Res. 265: 322-327.

Schwarcz, R., I. Creese, J. T. Coyle, and S. H. Snyder (1978) Dopamine receptors localized on cerebral cortical afferents to corpus striatum. Nature (Lond.) 271: 766-768.

Vandermaelen, C.P., and S.T. Kitai (1980) Intracellular analysis of synaptic potentials in rat neostriatum following stimulation of cerebral cortex, thalamus, and substantia nigra. Brain Res. Bull. 5: 725-733.

Wilson, C. J., H. T. Chang, and S. T. Kitai (1982) Origins of postsynaptic potentials evoked in identified rat neostriatal neurons by stimulation in substantia nigra. Exp. Brain Res. 45: $157-167$.

Wilson, C. J., H. T. Chang, and S. T. Kitai (1983a) Disfacilitation and long-lasting inhibition of neostriatal neurons in the rat. Exp. Brain Res. 51: 227-235.

Wilson, C. J., H. T. Chang, and S. T. Kitai (1983b) Origins of postsynaptic potentials evoked in spiny neostriatal projection neurons by thalamic stimulation in the rat. Exp. Brain Res. 51: $217-226$. 